\title{
PERANCANGAN SISTEM APLIKASI PENJUALANREFILL TINTA PADA PT. FENIXINDO GLOBAL MANDIRI
}

\author{
Opie Andin \\ Universitas Indraprasta PGRI \\ Jl. Raya Tengah No. 80, Kel. Gedong, Kec. Pasar Rebo, Jakarta Timur 13760, Jakarta \\ opieandin@gmail.com
}

\begin{abstract}
ABSTRAK
PT Fenixindo Global Mandiri merupakan perusahaan retail yang melengkapi komponen tinta printer. Kesalahan entri data penjualan sering ditemui selama proses pelaporan penjualan, yang menyebabkan kebingungan dalam data laporan penjualan. Tujuan dari penelitian ini adalah untuk merancang dan mengimplementasikan sistem aplikasi pengisian tinta yang dapat meningkatkan efisiensi dan produktivitas kasir dan bisnis dalam proses penjualan dan persediaan dan menggunakannya untuk pelaporan berbantuan komputer. Mengumpulkan data secara benar, akurat dan terpercaya. Metode penelitian yang penulis gunakan dalam penelitian ini mengarah kepada tujuan yang ingin dicapai dalam mengatasi permasalahan yang ada, penulis menggunakan metode Agile Development, yaitu sekelompok metode pengembangan software berdasarkan prinsip yang sama yang membutuhkan adaptasi pengembangan yang cepat terhadap setiap perubahan. Respon terhadap perubahan lebih baik daripada mengikuti rencana, agile berfokus kepada kecepatan ketika kasir menginginkan perubahan saat proses software. Hasil dari penelitian ini adalah adanya perangkat aplikasi yang dibangun dengan menggunakan bahasa pemrograman Java NetBeans dan penyimpanan data menggunakan database MySQL. Pada saat membangun sistem ini digunakan alat perancangan sistem yaitu diagram alir data kontekstual, null dan detail (DAD). Sistem aplikasi yang dirancang ini dapat membantu dan mempermudah staf administrasi dalam melakukan proses penjualan dan stok barang serta penyajian laporan di PT. Fenixindo Global Mandiri.
\end{abstract}

Kata Kunci:Penjualan, Java, MySQL, Refill, Sistem Aplikasi.

\begin{abstract}
PT Fenixindo Global Mandiri is a retail company that completes printer ink components. Sales data entry errors are frequently encountered during the sales reporting process, which causes confusion in the sales report data. The purpose of this research is to design and implement an ink filling application system that can increase the efficiency and productivity of cashiers and businesses in the sales and inventory process and use it for computer-aided reporting. Collect data correctly, accurately and reliably. The research method that the author uses in this study leads to the goal to be achieved in overcoming the existing problems, the author uses the Agile Development method, which is a group of software development methods based on the same principles that require rapid development adaptation to any changes. Responding to change is better than following a plan, agile focuses on speed when cashiers want changes during the software process. The result of this research is that there is an application device built using the Java NetBeans programming language and data storage using a MySQL database. When building this system, system design tools are used, namely contextual, null and detailed data flow diagrams (DAD). This designed application system can help and facilitate administrative staff in conducting the sales and stocking process and presenting reports at PT. Fenixindo Global Mandiri.
\end{abstract}

Key Word: Sales, Java, MySQL, Refill, Application System.

\section{PENDAHULUAN}

Teknologi adalah metode ilmiah untuk mencapai tujuan praktis dari ilmu terapan, yang juga dapat diterjemahkan sebagai alat untuk menghasilkan barang-barang yang diperlukan untuk kelangsungan hidup dan kenyamanan hidup manusia.

Seiring dengan kemajuan teknologi di berbagai bidang khususnya di bidang penjualan, pembelajaran seakan tidak ada habisnya. mereka adalah cara untuk menyelesaikan pekerjaan dengan cepat dan akurat.Pengertian personal komputer merupakan keliru satu perangkat elektro yg berfungsi buat memasak data sinkron menggunakan mekanisme-mekanisme yg sudah dirumuskan sebelumnya, sebagai akibatnya bisa membuat fakta yg berguna bagi kasirnya. 
Sejalan perkembangan teknologi komputer tidak terlepas juga dari teknologi percetakan, maka terciptalah teknologi alat untuk mencetak. Baik itu mencetak dokumen, laporan, surat menyurat maka lahirlah sebuah teknologi alat yaitu yang bernama printer.

Tentunya untuk mencetak dengan printer dibutuhkan tinta printer. Tinta printer adalah bagian penting dari printer yang berfungsi sebagai bahan baku mencetak.

Tinta merupakan berupa zat cair yg menciptakan proses pembentukan karakter/grafik terjadi dalam media kertas dan media sejenis. Tinta ini terdiri berdasarkan 4 kombinasi (cyan, magenta, yellow, black) dan 6 kombinasi (cyan, light cyan, magenta, light magenta, yellow, black).

PT Fenixindo Global Mandiri adalah sebuah perusahaan ritel yang bergerak dibidang pengisian ulang (refill) komponen tinta printer. Sebagai salah satu perusahaan ritel, permasalahan stok barang serta laporan penjualan menjadi fokus utama. Dalam proses laporan penjualan sering kali terjadi kesalahan dalam peng-input-an data penjualan yang mengakibatkan kerancuan data laporan penjualan.

Berdasarkan uraian latar belakang ini, maka perlu dibangun sebuah aplikasi sistem aplikasi penjualan berupa proses monitoring dan pencatatan laporan penjualan. Dengan dilakukan pencacatan laporan penjualan, diharapkan permasalahan-permasalahan tersebut dapat diselesaikan, dan akan mampu meningkatkan penjualan serta kecepatan dan ketepatan kerja karyawan dalam proses laporan penjualan dengan baik dan benar. Sehubungan dengan hal itu diangkatlah sebuah judul "Perancangan Sistem Aplikasi Penjualan Refill Tinta Printer pada PT. Fenixindo Global Mandiri" dengan menggunakan netbeans.

Tujuan dari penelitian ini adalah untuk merancang suatu sistem penjualan yang akan membantu meningkatkan efektifitas dan produktivitas kasir dan pelaku usaha dalam melakukan penjualan dan penyimpanan barang serta penyajian laporan melalui penggunaan fasilitas komputer sehingga dapat dilakukan pendataan yang akurat dan akurat.

Desain adalah langkah pertama dalam fase pengembangan produk atau rekayasa sistem. Desain adalah proses penerapan berbagai teknik dan prinsip untuk mendefinisikan secara rinci perangkat, proses atau sistem yang memungkinkan realisasi fisik. (Nadeak, dkk., 2016).

Perancangan sistem merupakan tahap di mana keahlian desain diperlukan untuk elemen komputer yang akan menggunakan sistem, yaitu pemilihan perangkat keras komputer dan program untuk sistem baru. (Muharto, 2016).

Penjualan adalah jumlah total yang ditagih kepada pelanggan untuk barang yang dijual oleh bisnis, termasuk penjualan tunai dan penjualan kredit (Hery, 2011).

Tujuan keseluruhan dari penjualan di perusahaan adalah untuk mencapai volume penjualan tertentu, untuk mendapatkan keuntungan dan untuk mendukung pertumbuhan dan perkembangan perusahaan. (Dharmmesta, 2014).

Referensi ini diambil peneliti dari jurnal yang berhubungan dengan rancangan sistem yang peneliti buat berjudul Perancangan Sistem Informasi Penjualan Pada Toko Udin Makasar Berbasis Java dan menyimpulkan dengan diterapkannya aplikasi penjualan pada toko udin makasar berbasis java merupakan langkah maju dalam penerapan teknologi informasi, rancang bangun aplikasi yang peneliti buat sebagai bantuan untuk pemilik toko udin makasar agar lebih tepat dan cepat dalam proses pendataan dan dalam transaksi barang yang dilakukan oleh pembeli (customer) (Adnyani, dkk., 2020).

\section{METODE PENELITIAN}

Metode penelitian yang penulis gunakan dalam penelitian ini mengarah kepada tujuan yang ingin dicapai dalam mengatasi permasalahan yang ada, penulis menggunakan Agile Development Method yang merupakan metode pengembangan inkremental yang berfokus pada pengembangan yang cepat, merilis perangkat lunak secara bertahap, mengurangi overhead proses, dan menghasilkan kualitas tinggi dan 
kode dalam proses pengembangan yang melibatkan langsung pelanggan. (Sommerville, 2011)

Konsep yang dipakai untuk sistem pelaksanaan ini merupakan menggunakan memakai agile development. Dengan teknik agile ini penulis dapat dengan mudah membuat suatu pengembangan sistem, mulai dari merencanakan dan mengumpulkan data (planning), desain sistem, uji sistem (testing),evaluasi dan penerapan sistem aplikasi serta pemeliharaannya.

Rancangan penelitian dan pembuatan sistem dilakukan dari bulan Maret 2021, dimulai dari perencanaan dan pengumpulan data, desain sistem, pengkodingan sistem, testing, evaluasi, perawatan maintenance juga penulisan laporan.

Penelitian dilakukan di PT. Fenixindo Global Mandiri yang terletak di Jl. Ir. Juanda No. 109 D, Tangerang, Cemp. Putih, Kec. Ciputat Tim., Kota Tangerang Selatan (Veneta System Ciputat), dimulai selama 4 bulan, penelitian dan pembuatan sistem dilakukan dari bulan Maret 2021 sampai dengan Juni 2021.

Bahasa pemrograman yang digunakan adalah java. Java adalah salah satu dari banyak bahasa pemrograman yang dapat berjalan di sistem operasi yang berbeda. (Nofriadi, 2015).

Netbeans adalah lingkungan pengembangan terintegrasi yang dikembangkan dengan bahasa pemrograman java (Andi, 2012).

MySQL atau dibaca "My Sekuel" dengan adalah sistem manajemen basis data relasional (RDBMS) yang merupakan aplikasi sistem yang melakukan fungsi pemrosesan data (Sibero, 2013).

XAMPP merupakan aplikasi bebas, yang mendukung banyak sistem operasi, adalah komplikasi menurut beberapa program (Aditya, 2011).

\section{HASIL DAN PEMBAHASAN}

Berdasarkan hasil penelitian masalah sebelumnya, penulis memberikan analisa permasalahan dari sistem pengelolaan data diantaranya:

1. Pengolahan data penjualan belum efektif dan efisien

2. Karyawansulit dalam melakukan pencarian stok barang saat pelaksanaan proses penjualan refill tinta.

3. Masih adanya kekurangan laporan penjualan baik itu harian dan bulanan.

4. Dibutuhkan aplikasi penunjang untuk melakukan pengolahan data

Dengan dasar identifikasi masalah tersebut diatas, maka penulis perlu membatasi ruang lingkup masalah ini sebagai berikut :

1. Merancang sistem penjualan yang efektif dan efisien.

2. Pencarian data stok barang ini hanya diaplikasikan untuk mempermudah karyawan dalam melakukan pencarian data stok barang.

3. Laporan (report) yang dibuat hanya mencakup laporan harian dan bulanan data penjualan.

4. Perancangan aplikasi dibangun menggunakan bahasa pemrograman java Netbeans IDE 8.2 dan database MySQL10.1.37.

\section{Diagram Konteks Sistem yang Diusulkan}

Berikut adalah gambaran sistem yang diusulkan untuk PT. Fenixindo Global Mandiri :

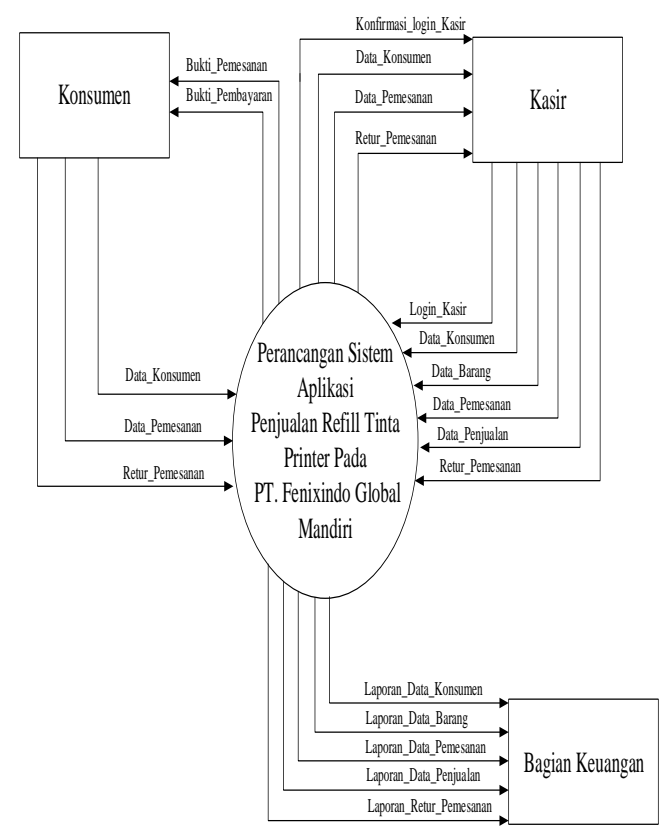

Gambar 1.Diagram Konteks Sistem 


\section{Diagram Nol Sistem}

Diagram nol merupakan gambaran proses sistem berjalan pada sistem penagihan yang menggambarkan tahap-tahap proses dari diagram konteks, yaitu :

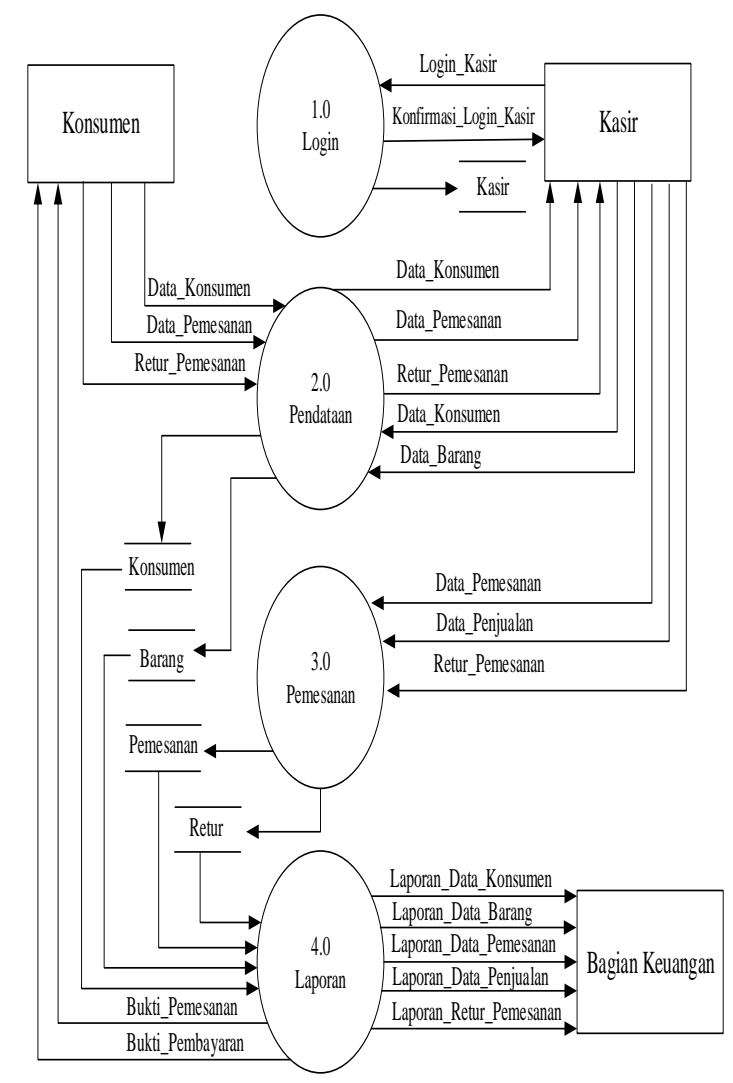

Gambar 2.Diagram Nol Sistem Entity Relationship Diagram (ERD)

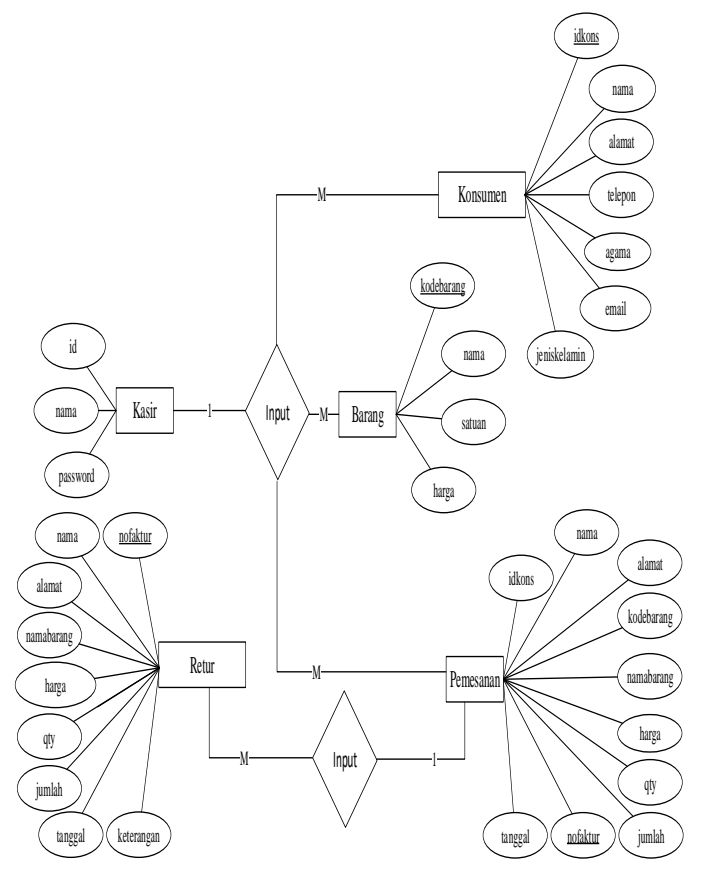

Gambar 3.ERD

\section{Normalisasi Tahap ke-1(1NF)}

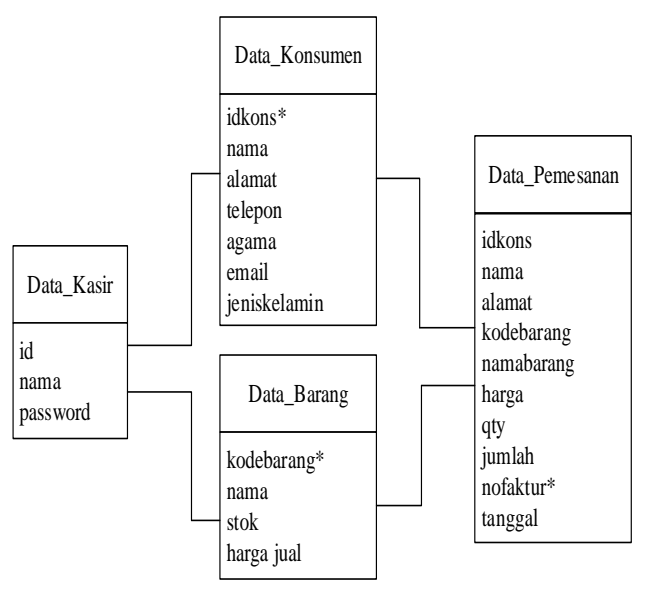

Gambar 4.Normalisasi Tahap ke-1(1NF)

\section{Normalisasi Tahap ke-2(2NF)}

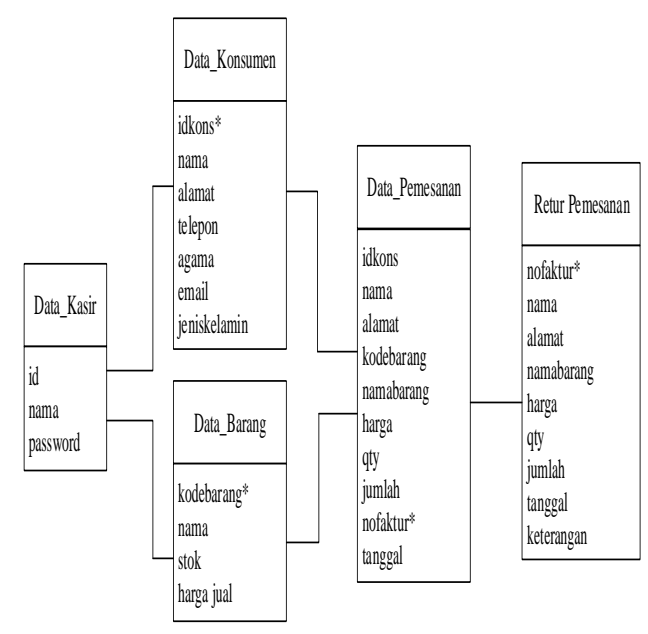

Gambar 5.Normalisasi Tahap ke-2(2NF)

\section{Tampilan Menu Login}

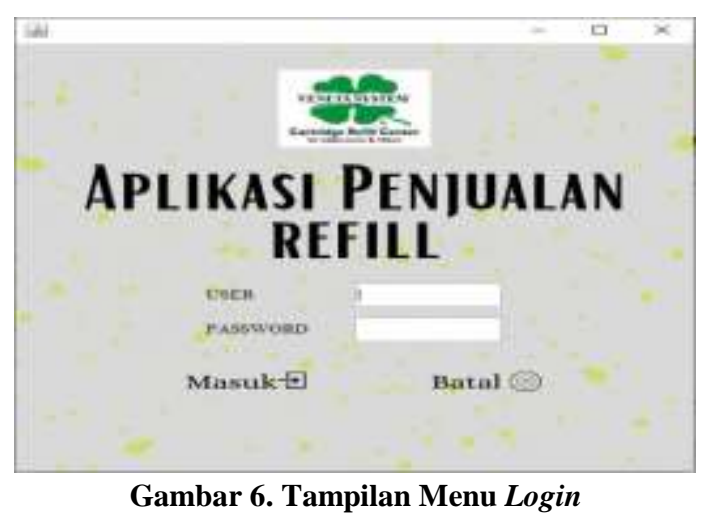

Tampilan menu login digunakan sebagai kata kunci sebelum kita memasuki program utama. Login digunakan sebagai kata kunci sebelum 
kita memasuki program utama. Agar tidak sembarangan orang dapat mengakses program ini. Sehingga dalam form menu kerahasiaannya tetap terjaga dengan baik.

\section{Tampilan Menu Utama}

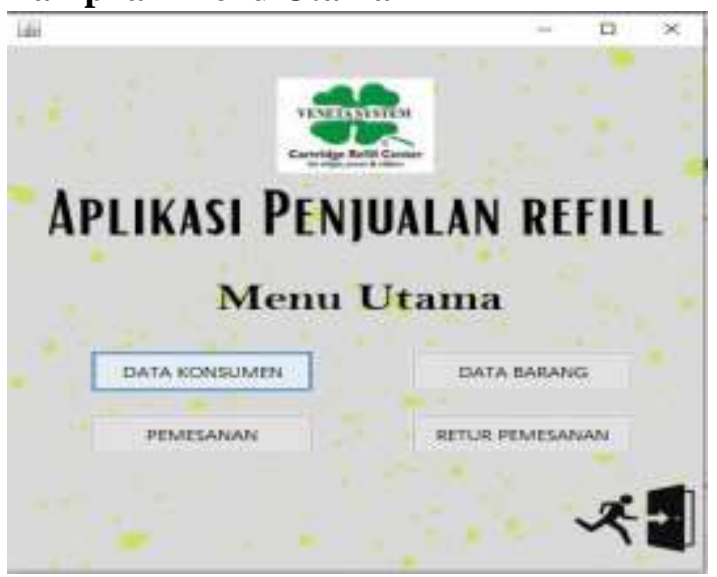

Gambar 7. Tampilan Menu Utama

Pada tampilan menu utama terdapat menu bar yaitu pemesanan, data konsumen, data barang dan retur pemesanan. Di dalam menu pemesana terdapat sub menu yang meliputi data-data pemesanan, kemudian di dalam menu data konsumen terdapat $s u b$ menu yang berisi data-data konsumen, di menu data barang terdapat sub menu yang berupa datadata stok barang, dan pada dalam menu returpemesanan terdapat sub menu yang meliputi data-data returpemesanan, sedangkan pada menu keluar berfungsi untuk keluar dari menu utama.

\section{Tampilan Form Data Konsumen}

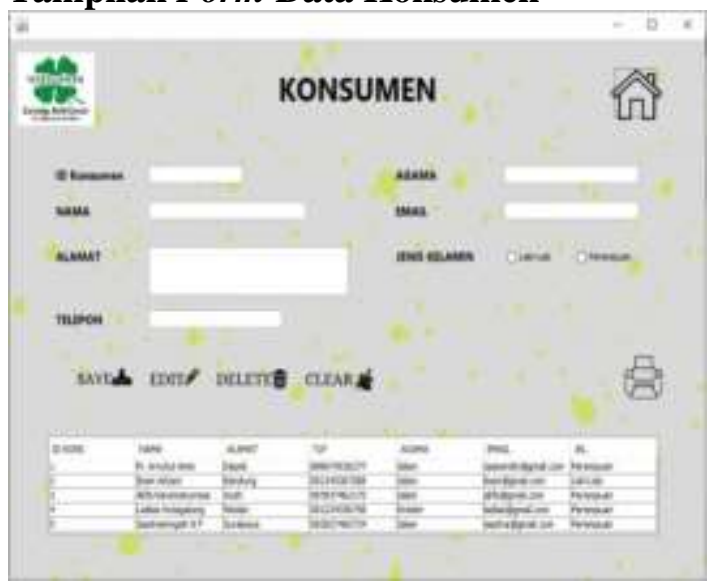

Gambar 8. Tampilan Form Konsumen

Form data konsumen digunakan untuk menginput data-data konsumen pada PT. Fenixindo Global Mandiri.

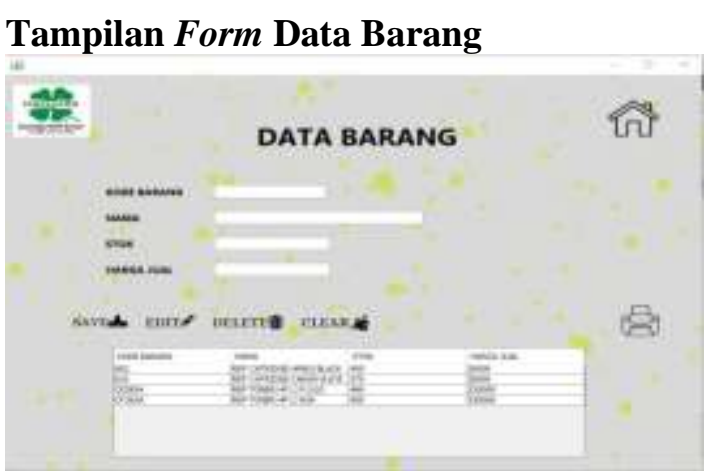

Gambar 9. Tampilan Form Barang

Form data barang digunakan untuk menginput data stok barang pada PT. Fenixindo Global Mandiri.

\section{Tampilan Form Data Pemesanan}

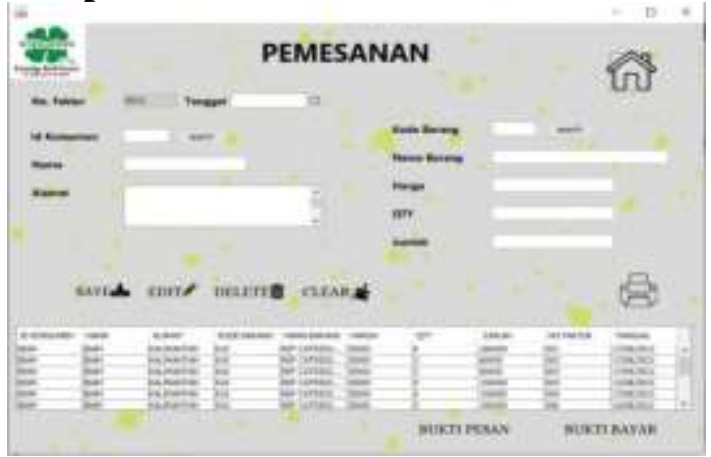

Gambar 10. Tampilan Form Pemesanan

Form pemesanan digunakan untuk melakukan transaksi pemesanan pada sistem PT. Fenixindo Global Mandiri.

\section{Tampilan Form Data Retur Pemesanan}

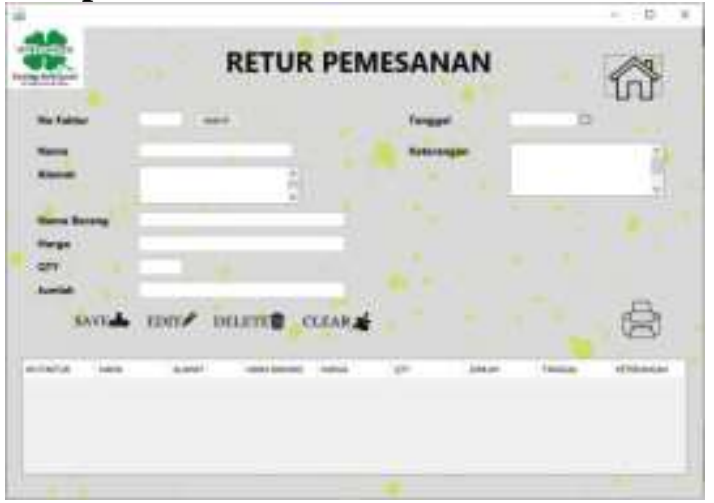

Gambar 11. Tampilan FormData Retur Pemesanan 
Form retur pemesanan digunakan untuk pengembalian stok apabila terjadi kesalahan input atau kerusakan pada barang.

\section{Tampilan Laporan Data Konsumen}

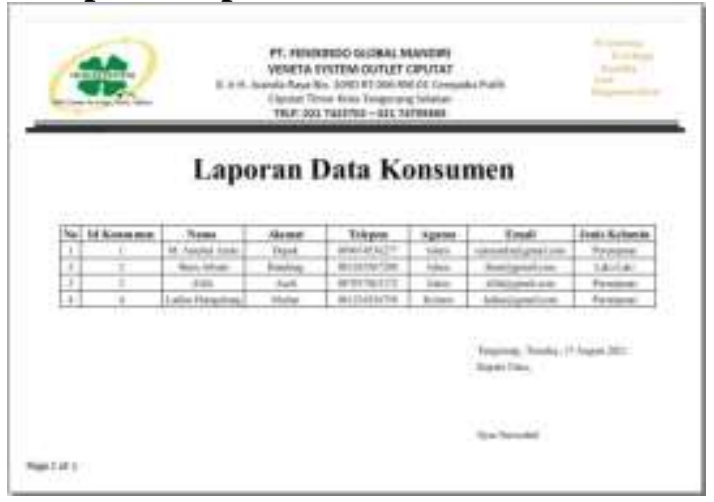

Gambar 12. Tampilan Laporan Data Konsumen

Pada tampilan ini menampilkan laporan data konsumen yang sudah dicetak.

\section{Tampilan Laporan Data Barang}

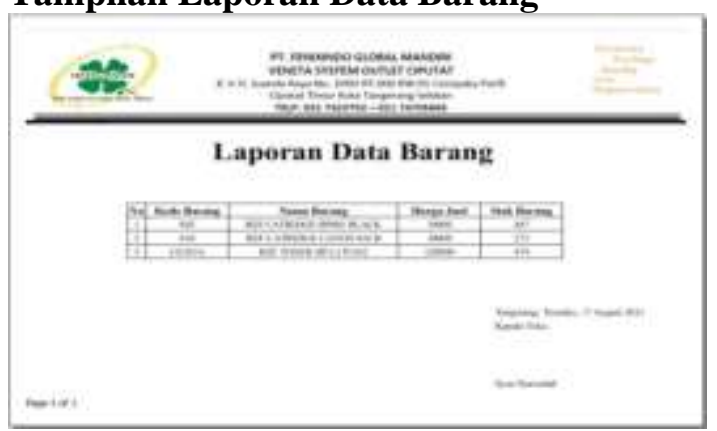

Gambar 13. Tampilan Laporan Data Barang

Pada tampilan ini menampilkan laporan data stok barang yang sudah dicetak.

\section{Tampilan Laporan Data Pemesanan}

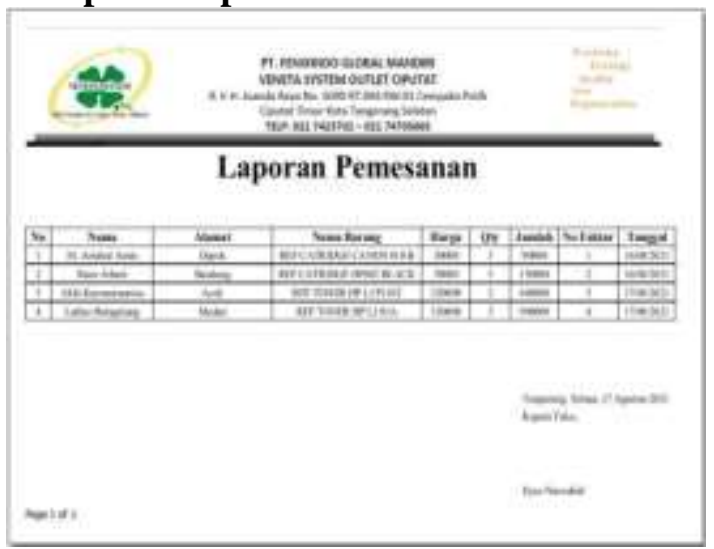

Gambar 14. Tampilan Laporan Data Pemesanan

Pada tampilan ini menampilkan laporan data pemesanan yang sudah dicetak.
Tampilan Laporan Data Retur Pemesanan

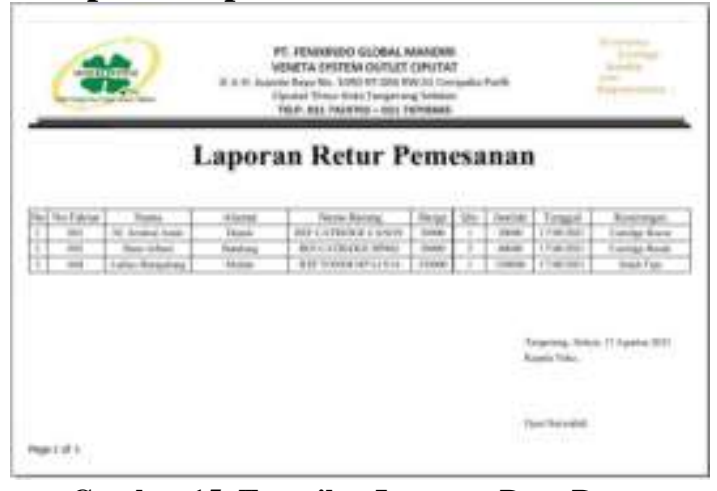

Gambar 15. Tampilan Laporan Data Retur Pemesanan

Pada tampilan ini menampilkan laporan data retur pemesanan yang sudah dicetak.

\section{Tampilan Bukti Pemesanan}

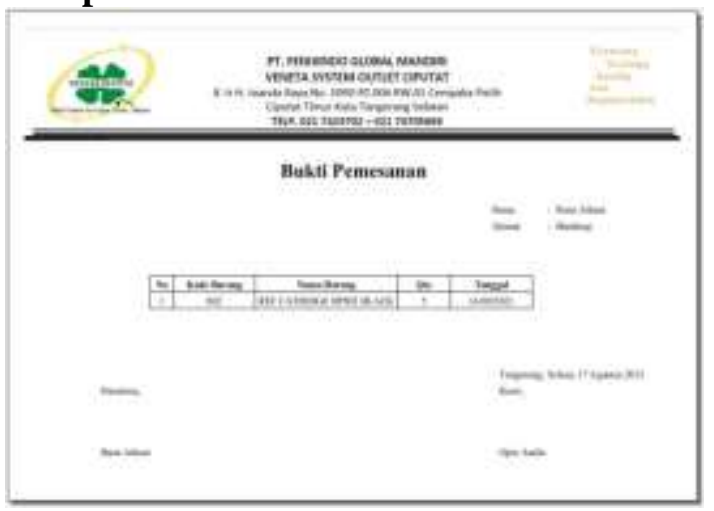

Gambar 16. Tampilan Bukti Pemesanan

Pada tampilan ini menampilkan bukti pemesanan yang sudah dicetak dan akan diberikan untuk konsumen.

\section{Tampilan Bukti Pembayaran}

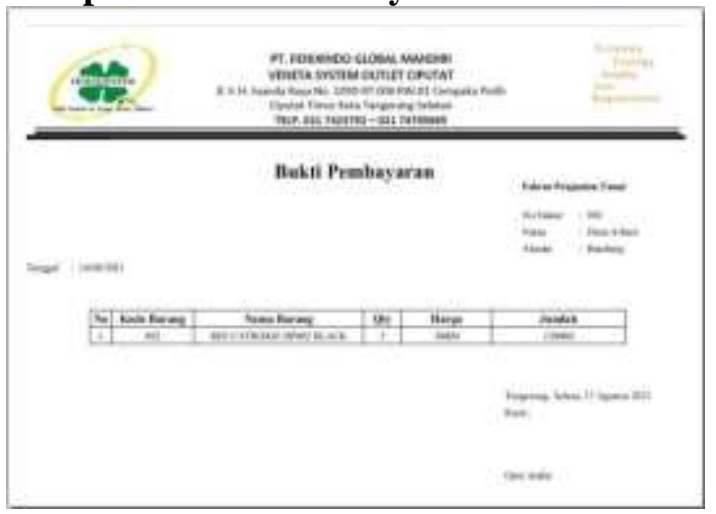

Gambar 17. Tampilan Bukti Pembayaran

Pada tampilan ini menampilkan bukti pembayaran yang sudah dicetak dan akan diberikan untuk konsumen. 


\section{SIMPULAN DAN SARAN}

Berdasarkan penelitian yang penulis lakukan saat ini, penulis memiliki tujuan penelitian dalam membuat Perancangan Sistem Aplikasi Penjualan Refill Tinta Printer Pada PT. Fenixindo Global yaitu :

Mengumpulkan data sebagai bahan penunjang untuk menemukan cara yang tepat dalam merancang suatu rancangan yang menangani sistem penjualan barang sesuai dengan kebutuhan dan permasalahan yang ada dengan bantuan aplikasi java.

Mencari dan mengetahui masalah serta kelemahan-kelemahan yang dihadapi perusahaan dalam pencarian data stok barang.

Mencari jalan keluar dalam mengatasi kelemahan dari proses pembuatan laporan harian dan laporan bulanan, dengan merancang sistem aplikasi penjualan refill tinta printer pada PT. Fenixindo Global Mandiri. Dengan diadakannya aplikasi dengan bahasa pemrograman Java Netbeans, membantu meningkatkan efektivitas dan produktivitas kerja kasir dan perusahaan dalam proses penjualan dan stok barang serta penyajian laporan dengan memanfaatkan fasilitas komputer, sehingga dihasilkan pendataan yang akurat dan tepat.

Sejalan dengan sistem usukan yang penulis buat, maka demi tercapainya tujuan dan sasaran yang diharapkan, maka penulis dapat memberi saran sebagai berikut :

Rancangan aplikasi penjualan refill tinta printer pada PT. Fenixindo Global Mandiri dapat dikembangkan kembali dalam hal point of sales (POS) atau penambahan database sesuai kebutuhan data penjualan barang.

Rancangan aplikasi penjualan refill tinta printer pada PT. Fenixindo Global Mandiri haruslah didukung oleh sistem agar mudah dan cepat dalam mengetahui segala informasi manajemen yang ada.

Rancangan aplikasi penjualan refill tinta printer pada PT. Fenixindo Global Mandiri dapat membantu pihak perusahan retail dalam penerimaan laporan penjualan harian dan bulanan dengan tepat dan akurat.

\section{UCAPAN TERIMAKASIH}

Terimakasih penulis ucapkan untuk PT. Fenixindo Global Mandiri beserta seluruh karyawan yang telah memberikan bantuan dan izin sehingga penelitian ini terlaksana dengan baik.

\section{DAFTAR PUSTAKA}

Aditya, A. N. (2011). Jago PHP \& MySQL Dalam Hitungan Menit. Dunia Komputer.

Adnyani, L. P. W., Juliana, \& Adriyansyah, R. (2020). Perancangan Sistem Informasi Penjualan Pada Toko Udin Makasar Berbasis Java. JURNAL FASILKOM, 10(3), 227-281.

Andi. (2012). Membangun Aplikasi Bisnis dengan Netbeans 7 . ANDI.

Dharmmesta, B. S. (2014). Manajemen Pemasaran. BPFE.

Hery. (2011). Teori Akuntansi (Cetakan 2). Kencana.

Muharto. (2016). Metode Penelitian Sistem Informasi. Deepublish.

Nadeak, B., Parulian, A., Pristiwanto, \& Siregar, S. R. (2016). Perancangan Aplikasi Pembelajaran Internet Dengan Menggunakan Metode Computer Based Instruction. Jurnal Riset Komputer (JURIKOM), 3, 54.

Nofriadi. (2015). Java Fundamental Dengan Netbeans 8.0.2. Deepublish.

Sibero, A. F. . (2013). Web Programming Power Pack. Mediakom.

Sommerville, I. (2011). Software Engineering (Rekayasa Perangkat Lunak). Erlangga. 